\title{
Total Temperature Measurements in Icing Cloud Flows using a Rearward Facing Probe
}

\author{
Juan H. Agui and Peter M. Struk \\ NASA Glenn Research Center
}

Tadas Bartkus

Ohio Aerospace Institute

\begin{abstract}
This paper reports on temperature and humidity measurements from a series of ice-crystal icing tunnel experiments conducted in June 2018 at the Propulsion Systems Laboratory at the NASA Glenn Research Center. The tests were fundamental in nature and were aimed at investigating the icing processes on a two-dimensional NACA0012 airfoil subjected to artificially generated icing clouds. Prior to the tests on the airfoil, a suite of instruments, including total temperature and humidity probes, were used to characterize the thermodynamic flow and icing cloud conditions of the facility. Two different total temperature probes were used in these tests which included a custom designed rearward facing probe and a commercial self-heating total temperature probe. The rearward facing probe, the main total temperature probe, is being designed to reduce and mitigate the contaminating effects of icing and ingestion of ice crystals and water droplets at the probe's inlet. The probe also serves as an air-sample inlet for a light absorption based humidity measurement. The paper includes a section which discusses total temperature and humidity measurement considerations, and another section which provides an analysis of the main probe's performance characteristics. A computational fluid dynamic model of the flow around the probe was also conducted to gain insight into the trajectory of the flow entering the probe inlet. The experiments included a series of tests in which the relative humidity of the facility flow was swept through with increasingly larger values. The data showed that the rearward facing probe can reasonably capture the flow's total temperature and humidity under mild to moderate icing conditions but can produce anomalous results under more intense icing conditions. The experimental data was also compared to an in-house developed thermodynamic model which takes into account the interaction of the main flow with the icing cloud. Comparison to the thermodynamic model showed that the rearward facing probe measured the predicted trends.
\end{abstract}

\section{Introduction}

When a jet engine encounters high altitude clouds containing high levels of ice water, it becomes susceptible to internal ice build-up resulting in significant performance losses and anomalies. Engine icing is a complex physical phenomenon involving the interaction of the different phases of water coupled with the hot engine environment, its internal surfaces and rotating components. While

Page 1 of 12 vigorous research and testing efforts are being devoted to engine icing, the physics of this phenomenon is currently still not well understood. Primarily, the interaction of ice crystals and/or water droplets with the high temperature environment in the engine causes intricate changes in the local thermodynamic properties of the airflow and the ice and water phases, and under certain conditions can promote the formation or accretion of ice onto the internal surfaces of the engine.

Icing wind tunnels, such as NASA's Propulsion Systems Laboratory (PSL), can generally simulate the atmospheric conditions related to engine icing, aiding researchers in their understanding of this phenomenon. These tunnels can closely generate the high altitude atmospheric aerothermal conditions and icing cloud characteristics encountered in flight, although the exact properties of the ice crystal particles (e.g. morphology and size) and supercooled liquid (SCL) water droplets in the atmosphere may not entirely be captured. Notwithstanding, much insight is gained by experimentally studying the interactions among the flow, the icing cloud and engine components in these facilities.

Physical models of the icing cloud and atmospheric flow interactions have been previously reported. Bartkus et al. [1,2] reported on both experimental data obtained in the NASA PSL and numerical results obtained using a thermodynamic model (Thermodynamically Coupled Air-Droplet Icing Wind Tunnel Model, TADICE) that demonstrated changes in air temperature and humidity as a result of the thermal exchange with the icing cloud. A more recent study [3], compared total temperature and humidity measurements of the cloud flow using a rearward facing probe (RFP) with the TADICE model which showed reasonably good agreement. The experimental data however was limited to a few tests within a limited range of parameters.

A series of new experiments were recently performed at PSL to study the ice accretion processes on a NACA 0012 airfoil, under controlled simulated icing cloud flows. More details of these experiments is provided in an accompanying paper by Struk et al. [4]. As part of these tests, the flow's aerothermal and cloud characterization were performed utilizing multiple probes to determine ice/water content and its spatial distribution, ice crystal particle size distribution, melt ratio, total temperature, and humidity levels in the test section. This paper will focus on the total temperature and humidity results obtained with the RFP. 


\section{Test setup and methods}

NASA Glenn's PSL, Test Cell \#3, is capable of simulating the iceladen flight-altitude flow conditions required to investigate icing related performance-losses in jet engines. Icing clouds are generated by a series of spray nozzles distributed in the plenum cross section upstream of the test section duct which introduce dispersed jets of water droplets into the main facility flow. The water droplets can either partially or fully freeze depending on thermodynamic flow conditions as they travel downstream into the test section. Under certain conditions, supercool liquid water droplets can also be generated and sustained during these tests. The reader is referred to references [5] and [6] for more details on the characteristics of the spray bar system that generates the icing clouds. By the time the cloud arrives at the test section it has interacted for some period of time with the main flow and consequently the flow's thermodynamic properties and the mixed phase distribution of the cloud have undergone changes.

A suite of intrusive probes were introduced, one at a time, into the flow just downstream of the facility's exit duct through a newly designed traversing system (see Ref. [4] for a description of the traversing system) that made possible multiple probe samplings without stopping the flow. These particular instruments were used to measure the cloud's ice/water content, particle size distribution, and the flow's total temperature and humidity level. Each probe was positioned into the flow at the same test station where a NACA0012 airfoil model was separately introduced to study the ice accretion and erosion processes. Non-intrusive probing techniques were also setup at the same test station to measure particle size distribution and to characterize the spatial distribution of the ice. The focus of this paper is on the results of the local total temperature and humidity measurements taken during the icing cloud spraying events.

\section{Total temperature measurement and calibration}

Total temperature measurements are particularly challenging in this test environment as described in Ref. [3]. This is because of the potential to ingest ice crystals or liquid water at the probe's inlet and for ice to accrete on the probe's body, which can result in a contaminated probe measurement. There are a couple of techniques to mitigate against these effects, which for instance involve inlet selfheating [4] or a rearward facing inlet probe design [3]. Probes utilizing both techniques were used in the current experimental test campaign.

Total air temperature consists of two components, the static and dynamic (i.e. due to kinetic energy of the flow) temperature:

$$
T_{0}=T_{S}+\frac{V^{2}}{2 C_{p}}
$$

For most total temperature probes, the temperature measurement deviates from the true total temperature because of viscous effects and incomplete thermal recovery of the flow. Viscous flow losses in the form of turbulence or secondary flows upstream of the probe inlet can alter the dynamic component of total temperature. At the same time, thermal losses from surfaces ahead of the probe that act as thermal sources and sink paths can also alter the true total temperature of the flow that ultimately reaches the probe's sensor. Radiative thermal losses to the environment were considered to play a minor role for icing conditions. Lastly, the effect of ice accretion on the probe body can lead to both thermal and viscous loss effects. Ice Page 2 of 12 crystal and water droplet ingestion at the probe inlet can cause even more drastic changes to the measured total temperature. To compensate for these effects, except for icing of the probe and ice crystal/water droplet ingestion, calibration tests performed under known and controlled conditions were used in the conversion of the experimental data.

The RFP probe, described in Ref. [3], was used in the present tests to measure the total temperature of the flow. A picture of the probe installed on a support strut in the PSL is shown in Fig. 1. To reduce the amount of thermal loss from icing on the outside of the probe, the RFP in reference [3] was modified by replacing the stainless steel inlet tube (an extension tube attached to the main body of the probe) with one that was 3D printed using Acrylic Styrene Acrylonitrile (ASA) material. The choice of a non-conducting 3D material helped to lessen the heat transfer between any ice on the outside of the inlet tube and the flow being ingested. The temperature is measured using an RTD sensor which has an accuracy of better than $0.5^{\circ} \mathrm{C}$. In addition to measuring temperature, humidity was measured by the same probe by drawing the atmospheric flow at 3 slpm (standard liters per meter) at the probe's inlet through a small pump, directing the flow through a hygrometer to measure the humidity level. The hygrometer (Model WVSS-II by Spectra Sensors) uses a tunable diode laser absorption spectroscopy methodology to continually measure the water vapor in the air passing through the device.

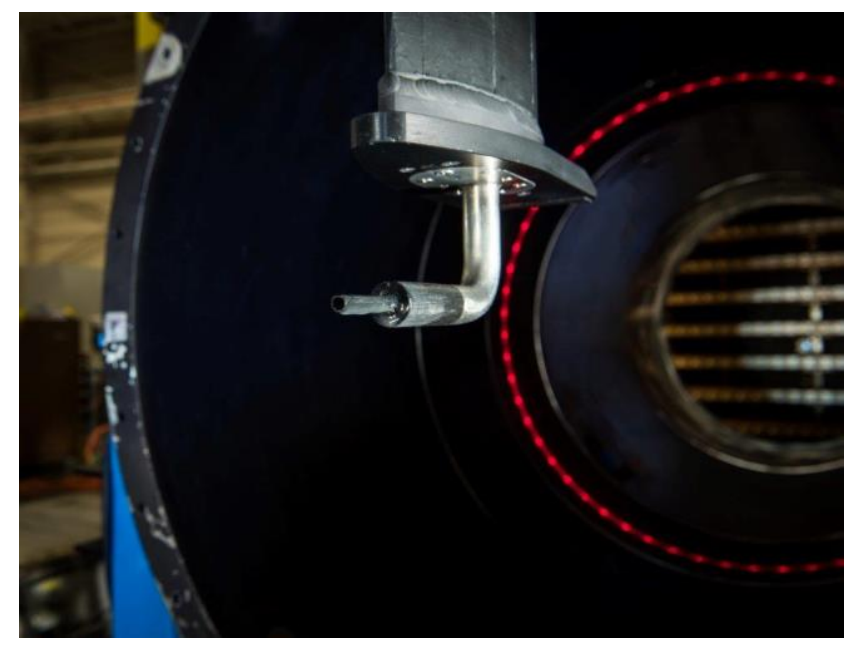

Figure 1. Picture of the Rearward Facing Probe as installed in the PSL.

The RFP was calibrated in the PSL by using the dry (no cloud) condition portion of the test runs. A recovery correction variable (Ref. 7) defined as,

$$
\eta=\frac{T_{0}-T_{r}}{T_{0}}
$$

was adapted in the calibration analysis. Here $T_{0}$ refers to the true total temperature, at the test section, while $T_{r}$ refers to the recovery total temperature (i.e. the measured value), associated with the response of the RFP's temperature sensor. All temperatures are in absolute scale.

Figure 2 shows a plot of the RFP's recovery correction, $\eta$, as a function of Mach number. The plot shows a typical non-linear increase in recovery correction with Mach number (e.g. see Ref. 7) ranging from about 0.00275 to 0.0205 . The plots at different Relative Humidity $(\mathrm{RH})$ ranges are plotted to show the dependence of $\eta$ on 
this parameter. For the most part, the recovery correction showed a slight amount of scatter in the low Mach number cases, and a tight grouping at the highest Mach number. The level of RH did not effectively impact this trend. A power curve fit $\left(\eta=A M^{B}\right)$ going through all the data points is given in the Fig. 2, with values of $0.06916 \pm 0.00423$ and $2.1195 \pm 0.0826$ for constants A and B respectively. Despite a small amount of scatter, the data seem to fit a functional dependence mainly on Mach number.

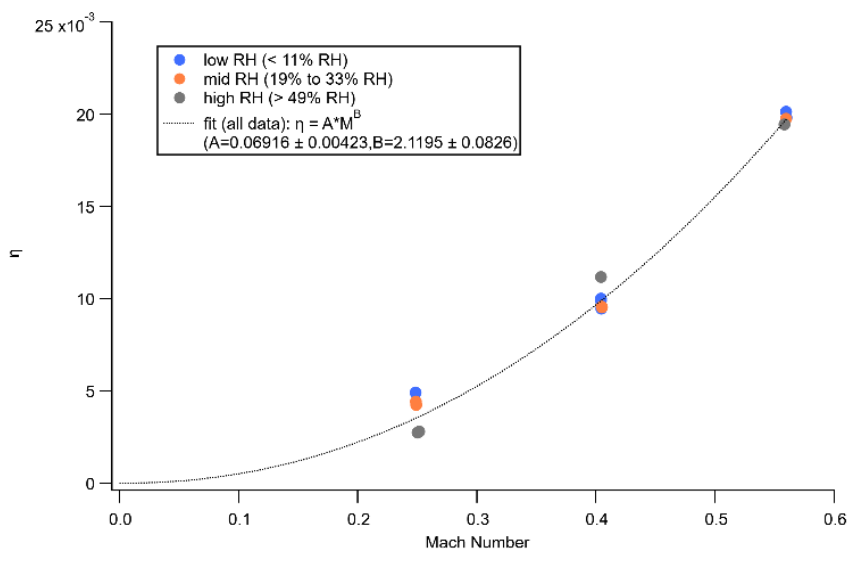

Figure 2. Rearward Facing Probe Recovery Correction

Equation 2 can be used to derive an expression for the change in total temperature when the icing cloud interacts with the main flow, which is given by

$$
\Delta T_{0}=T_{0,2}-T_{0,1}=\frac{T_{R F P, 2}}{1-\eta_{2}}-\frac{T_{R F P, 1}}{1-\eta_{1}}
$$

where subscripts 1 and 2 refer to the pre-spray and spray-on conditions respectively, and $T_{r}$ has been replaced by $T_{R F P}$ which is the temperature measured by the RFP. Therefore, the change in total temperature, $\Delta T_{0}$, depends on the "spray-on" and "pre-spray" temperatures measured with the RFP, as well as $\eta$ values at these two points. The value of $\eta_{I}$ is found by evaluating Eq. 2 using the prespray $T_{R F P, 1}$ and $T_{0,1}$, where $\mathrm{T}_{0,1}$ was given by the plenum total temperature. The value of $\eta_{2}$ however required an iterative calculation since it depends on Mach number (as per the curve fit), which in turn depends on $T_{2}$. The Mach number changes because of the cooling effect from the interaction with the icing cloud. In fact, the Mach number should increase due to the lower static temperature at this condition. To find the new Mach number at point 2, we can assume that the drop in temperature only affects the static component of total temperature. Therefore, the change in temperature measured with the RFP $\left(\triangle T_{R F P}\right)$ can be subtracted from both the static and total temperature, to provide $M_{2}$.

$$
M_{2}=\sqrt{\left[\frac{\left(T_{0,2}-\Delta T_{R F P}\right)}{\left(T_{s, 2}-\Delta T_{R F P}\right)}-1\right] \frac{2}{\gamma-1}}
$$

The new Mach number leads to a change in recovery correction. The new $\eta$ is then used to calculate a new $T_{0,2}$. The final values of $T_{0,2}$ can be found recursively by following this procedure a few times until the new corrected $\mathrm{T}_{0,2}$ is within and error margin of the previous $\mathrm{T}_{0,2}$. Typically, this took only one or two iterations, with temperature corrections to within less than $0.001 \mathrm{C}$.
Table 1 in the appendix shows a comparison of the calculated $\Delta T_{0}$ obtained with equation 3 and by differencing the $T_{R F P}$ readings (i.e. $\left.T_{R F P, 2}-T_{R F P, 1}\right)$, accounting for the drift in the plenum total temperature.

\section{Other probe considerations}

Figure 3 shows a plot of measured total temperature taken with the RFP in a flow velocity of $185 \mathrm{~m} / \mathrm{s}$ or Mach number of 0.56 . Prior to the arrival of the icing cloud, as indicated by the Spray On status, the probe's total temperature, $T_{R F P}$, is fairly lower than the facility's plenum total temperature. This condition is attributed to the probe's recovery correction as discussed in the previous section. At this Mach number, the recovery correction is substantial as indicated in Fig. 1. The passage of the icing cloud over the probe produces a transient change in total temperature, $\Delta T_{0}$, that takes place over a time window, characterized by the time constant $\tau$ based on reaching $62.3 \%$ of the total temperature change, before reaching a new equilibrium temperature. After the cessation of the cloud, the total temperature recovers back to nearly the same total temperature before the arrival of the spray over approximately the same time constant during the spraying event. The time constant is a characteristic of the probe material and design, which are coupled into the probe's heat capacity.

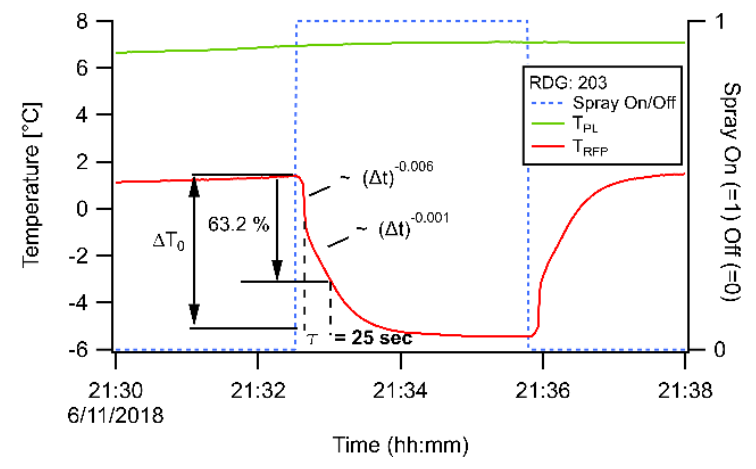

Figure 3. Typical Total temperature signal obtained with the Rearward Facing Probe. The test conditions were $\mathrm{M}=0.57$ at $\mathrm{P}_{0}=44.8 \mathrm{kPa}$.

Upon close inspection, the transient response of the probe is shown to exhibit an initial precipitous drop in temperature with a decay rate of $(\Delta t)^{-0.006}$, followed by a more gradual drop with a decay rate of $(\Delta t)^{-0.001}$ that asymptotes to the new equilibrium value. The time difference, $\Delta t$, in the above starts at the beginning of each of the two different decay phases respectively. The two associated temporal decay rates are shown in Fig. 3. As discussed, the response has to do with the thermal exchange and aerodynamic interaction among the flow, icing cloud and the probe body. Compared to a forward facing probe, this interaction is rather extensive for the RFP since the flow traverses over a major portion of the probe's body before it enters the internal inlet region where it encounters the temperature sensor.

For comparison, Fig. 4 shows the response of a commercial Total Air Temperature (TAT) probe (Rosemount TAT Probe Model 102LA2AG) [7], also used in this test campaign, during a separate spraying event (although at a smaller Mach number, $\mathrm{M}=0.4$ at $\mathrm{P}_{0}=44.8 \mathrm{kPa}$ ) showing a much shorter response time and faster decay rate of $(\Delta t)^{-0.002}$. The time difference, $\Delta t$, in this case starts from the point in time when $T_{0,}$ ref is reached during the spraying event. By comparison, the decay rate of the TAT was faster by an exponential factor of 2 to that of the RFP. The TAT probe's inlet directly faces 
the incoming flow and is located upstream of the probe's body rather than downstream as in the case of the RFP. A de-ice self-heating function of the probe is used to prevent icing over the body of the probe and to slightly heat up the inlet flow. Because of the selfheating, the probe's temperature reading is elevated above the facility's plenum temperature. The higher value temperature is not appropriate in determining changes in total temperature since it is artificially elevated. Rather, the measured temperature prior to applying the self-heating can be used as the reference total temperature, $T_{0, r e f}$, prior to the arrival of the icing cloud. The difference between higher temperature when the deice heat is turned on and $T_{0, r e f}$ is referred to as the de-ice heat temperature correction. After the temperature drops below the reference temperature as the icing cloud is sensed, the probe exhibits a slower response. By comparison, the time response of the TAT probe during this phase is still faster than that of the RFP's, as indicated previously. In light of this effect, the total temperature change from the Goodrich TAT probe reported in the Results section will be given by the difference between "spray on" temperature and $T_{0}$,ref. The authors conjectured that the probe self-heating due to deice heat was not felt by the air once the cloud activated since the probe was running wet (i.e. it did not evaporate the impinging water / ice). However, the effect of deice heat on the final air temperature measurement is still not well understood.

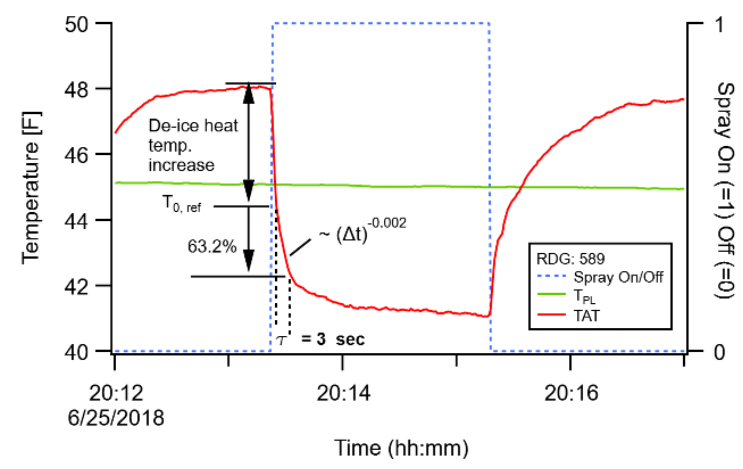

Figure 4. Typical Total temperature signal obtained with the TAT probe. The test conditions were $\mathrm{M}=0.40$ at $\mathrm{P}_{0}=44.8 \mathrm{kPa}$.

Figure 5 shows a typical humidity measurement obtained by analyzing the flow ingested by the RFP through a hygrometer. The humidity is given in terms of the Mass Mixing Ratio (MMR), defined as the ratio of mass of water vapor to mass of dry air.

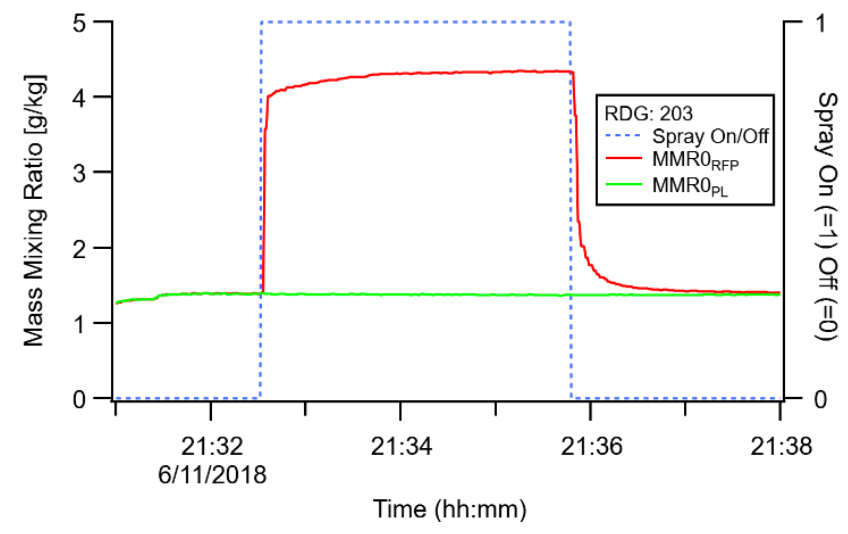

Figure 5. Typical humidity measurement in terms of Mass Mixing Ratio obtained with the RFP. The test conditions were $\mathrm{M}=0.56$ at $\mathrm{P}_{0}=44.8 \mathrm{kPa}$.
The probe's humidity measurements $\left(\triangle M M R_{R F P}\right)$ were compared against the humidity measurements made in the facility's plenum section $\left(\triangle M M R_{P L}\right)$. The plenum humidity remains fairly constant throughout the spraying event, as well as in the pre and post spray periods. While the plenum humidity was measured upstream of the test section (upstream of the spray bars), in the absence of icing cloud spraying the humidity level was not expected to change appreciably by the time the flow reached the test section and therefore the two humidity measurements should have been about the same. As seen in the figure, the two humidity measurements agree quite well before the icing cloud arrives although the agreement was not as good for all cases particularly for the highest plenum humidity values. When the icing cloud reaches the test section, where the probe is positioned, the humidity level rises almost instantly, within 2 seconds, and then gradually reaches a new equilibrium level. After the icing cloud spray is turned off, the flow's humidity levels quickly dropped back to the pre-spray value, matching the humidity of the plenum. Most of the humidity signals appeared to be clean and well resolved under no icing to low icing conditions. However, there were a few cases where the humidity levels read artificially high when no icing cloud was present. In those cases, it was suspected that there might have been an air leak in the tubing line and associated connectors used between the probe and the hygrometer instruments. In those cases, caution was use in the interpretation or omission of the humidity data.

There were instances during the test campaign where the probe's total temperature and humidity measurements did not recover to the prespray values. These typically took place when ice was found to accrete on the probe, although this was not always the case when ice accretion occurred. There was also the possibility of ingestion of water droplets from the flow or from water run back on the probe body into the inlet (which was unverified). Figure 6 shows an image of the RFP with ice built up during a spray test. In these instances, only cases in which mild accretion and small differences between the pre-spray and the post-spray total temperatures took place were used in the analysis.

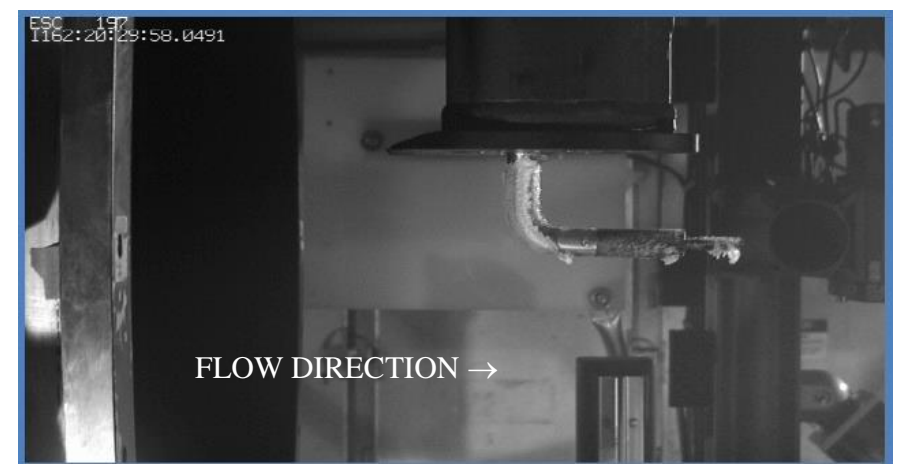

Figure 6. Picture of ice accreted on the RFP body positioned just downstream of the PSL exit duct.

An example of a total temperature signal exhibiting the effects of icing on the probe is shown in Fig. 7. This signal can be compared to the nominal $T_{R F P}$ signal shown in Fig. 3, in the absence of icing. The pre-spray temperature starts out at a value below the plenum total temperature similar to other runs with the same starting conditions. After the icing cloud was turned on, the initial response of the probe was significantly slower than the nominal case show in Fig. 4. In the later stage of the spraying event, the temperature continued dropping although at a much slower rate and never reached an asymptotic value until the freezing point temperature was reached. The total temperature did not recover after the icing spray stopped, instead 
dropping even slightly lower in value. The humidity measurement for this same test case was also anomalous. The initial reading was significantly lower than the humidity level in the plenum. After the arrival of the icing cloud, the humidity rose at a substantially slower rate and continued increasing until the end of the icing cloud event where the value reached close to the level in the plenum. After the passage of the icing cloud, the humidity measured by the probe quickly dropped in value closer to the initial humidity value. Test cases exhibiting these icing related effects were omitted from the data analysis.

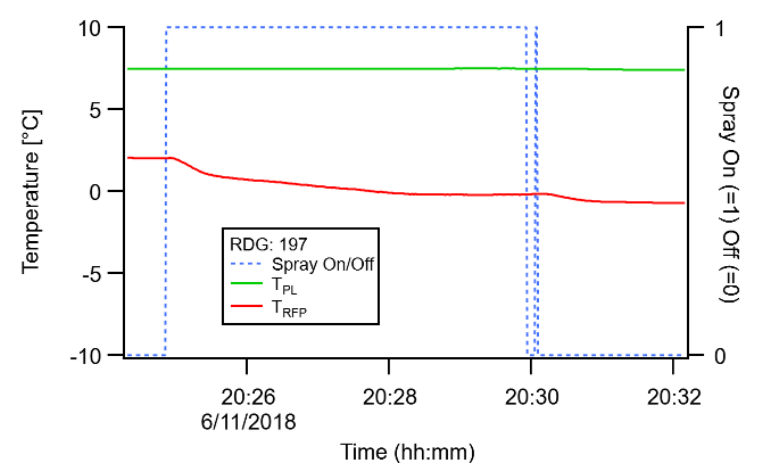

(a)

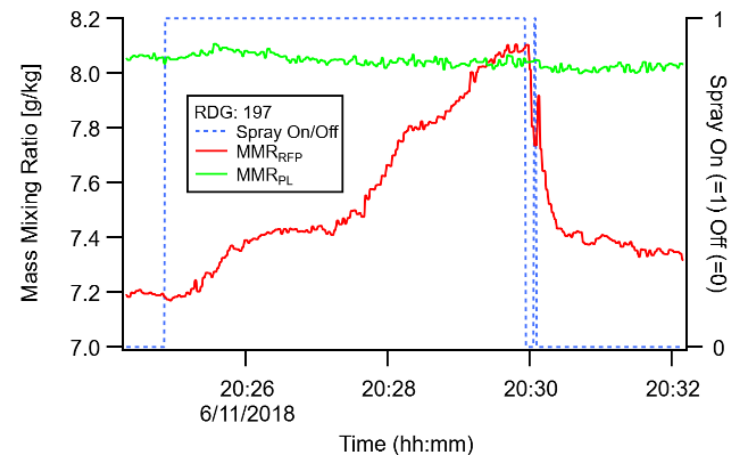

(b)

Figure 7. (a) Total temperature and (b) humidity measurements obtained in a test when icing was observed on the probe. The test conditions were $\mathrm{M}=0.56$ at $\mathrm{P}_{0}=44.8 \mathrm{kPa}$.

\section{Aerodynamic modeling of RFP}

The flow around the RFP was modeled to gain insight into the flow trajectory around the probe body and at the inlet. The lowest Mach number case, 0.25, was modeled using OpenFOAM's 3-D steadystate incompressible $\kappa-\omega$ turbulent model [8]. For this model, the probe geometry was embedded in a flow matching the lowest velocity test conditions of $85 \mathrm{~m} / \mathrm{s}$ longitudinal velocity and static pressure of $44.8 \mathrm{kPa}$ (6.5 psia). At this low Mach number, the incompressible turbulent code can adequately capture the aerodynamic flow field around the probe. The boundary condition on the side boundaries of the computational domain were set up as slip boundary conditions with a constraint uniform velocity matching the internal field. The downstream outlet boundary was set up as a pressure outlet boundary condition. A no-slip wall boundary condition was applied around the probe body. The probe inlet was Page 5 of 12 modeled as an outlet flow condition with a specified constant flowrate.

Figure 8a shows a center-plane contour plot of the velocity field around the probe model, with the probe inlet (tip of the probe) facing downstream. In the leading edge region of the probe, the velocity decelerates in the longitudinal (positive $\mathrm{x}$-direction) direction to values less than half the free stream velocity. In the wake region of the upright section of the probe body, very low as well as negative velocities were produced, indicating flow reversal and likely recirculation behavior. Vortical shedding is dominant in the wake flow of a cross-stream cylinder. A periodic vertical wake structure can also be seen along the upright length of the probe. The probe's suction inlet velocity, which is only about to $2 \mathrm{~m} / \mathrm{s}$ based on a suction flow rate of $3 \mathrm{slpm}$, is captured in the contour plot although it is somewhat masked in the contour interpolation by the larger free stream velocity and velocity gradients dominant in the wake region.

Figure $8 \mathrm{~b}$ shows the trajectory of the streamlines that enter the near wake region of the probe inlet prior to being ingested at the inlet. As plotted, these streamlines originate upstream of the probe and terminate at the inlet region. The trajectory of the streamlines show that the flow entering the inlet comes into very close contact and interacts with the surface of the probe body. Therefore, under icing conditions where ice can accrete on the surface of the probe, the flow may be convectively cooled prior to entering the inlet and result in a lower measured total temperature. This could explain the variation in the icing probe signal when ice contamination occurred as discussed in the previous section.

The modeling of ice cloud and icing related phenomenon can provide insight to better characterize the contamination effects on the probe. Future modeling efforts can include modeling of ice-crystal particle or water droplet injection into the flow, which would indicate the possibility of particle or droplet ingestion into the probe's inlet. This phenomenon can adversely affect the probe's measurements because it can alter the heat transfer physics at the temperature sensor and artificially enhance humidity levels. Additionally, the effects of water film formation on the probe body due to ice accretion and melting, and associated run back, where it can reach the probe inlet are also worth exploring. The understanding gain from modeling could lead to probe modifications that can improve the accuracy and reliability of the total temperature and humidity measurements.

\section{Results}

The 2018 PSL experiments produced a number of altitude icing cloud flows under well-characterized conditions to characterize the resulting ice shapes on an airfoil model. Four different flow conditions were produced where the upstream relative humidity was the primary parameter varied. These tests were called relative humidity sweeps.

\section{RH Sweeps}

Figures 9 shows plots of $\Delta T_{0}$ and $\triangle M M R$, for four relative humidity sweeps. The sweeps were run at three velocities, $85 \mathrm{~m} / \mathrm{s}, 135 \mathrm{~m} / \mathrm{s}$, and $185 \mathrm{~m} / \mathrm{s}$. In addition, three tests were conducted at an altitude pressure of $44.8 \mathrm{kPa}(6.5 \mathrm{psia})$ while a fourth test case was performed at $87.6 \mathrm{kPa}(12.7 \mathrm{psia})$. All tests were conducted at a target plenum temperature of $7.2^{\circ} \mathrm{C}\left(45^{\circ} \mathrm{F}\right)$. Additionally, the results of the TADICE simulation at the corresponding test points are superimposed on the graphs for comparison. The appendix provides 
the tabulated data for these plots (Tables 1 and 2 in the appendix provide the experimental data and calculations for $\triangle T_{0}$ and $\triangle M M R$ respectively, and Table 3 provides corresponding input conditions to the TADICE model).

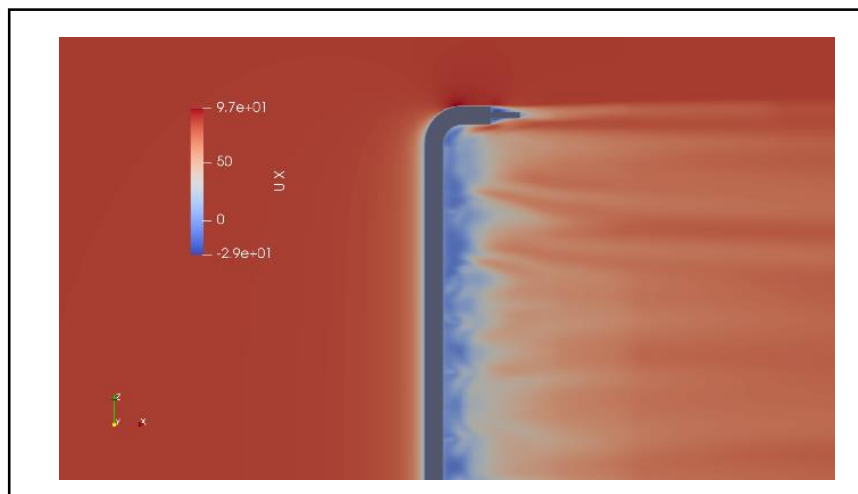

(a)

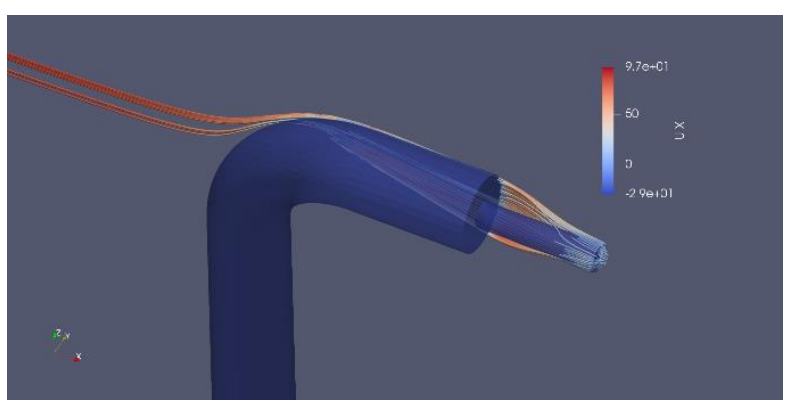

(b)

Figure 8. CFD simulation of the flow over the RFP showing (a) contour plot of the velocity flow field on the center plane and (b) streamlines entering the probe's inlet region.

The plots of $\Delta T_{0}$ for all four test conditions comparing experimental and simulation data are shown in Figs. 9a-9d. The first case at the lowest velocity and a plenum pressure of $44.8 \mathrm{kPa}$, Fig. 9a, is typical of all four test cases in that the flow cools at the test section after the cloud is turned on. The temperature change decreases in magnitude with increasing RH. Note that the reason $\Delta T_{0}$ values are negative in all these cases is because the interaction with the icing cloud produces a cooling effect on the flow due to evaporation. The plots in this case show that the simulation data predicted larger temperature changes compared with the experimental results. In the mid-velocity case, Fig. $9 \mathrm{~b}, \Delta T_{0}$ values are generally greater in magnitude than in the lowest velocity case. The experimental and simulation data sets in Fig $9 \mathrm{~b}$ are in closer agreement compared to Fig. 9a, although there is still a small gap between them at the higher RH conditions. In addition, test points from the TAT probe obtained in a $R H$ sweep at this test condition are also plotted and appear to be in close agreement with the RFP. Both experimental data sets are also in relatively good agreement with the simulation data. In the highest velocity case, Fig. 9c, the RFP data is again in close agreement with the simulation data and values of $\Delta T_{0}$ are smaller in magnitude than in the lower two velocity cases. Lastly, in the higher pressure case, Fig. 9d, the change in $\Delta T_{0}$ was less sensitive to RH\%, both experimentally and in the simulation. The reader is cautioned that there is a lack of data between $10 \%$ and $50 \% \mathrm{RH}$ in this particular atmospheric pressure case, and therefore the actual trend cannot confidently be established. At this pressure, the $\Delta T_{0}$ at the lowest Page 6 of 12
Mach number were also significantly smaller in magnitude than in the cases at $44.8 \mathrm{kPa}$. There is also a wider discrepancy between the simulation and test data for this test condition.

Figures 9e-g show the corresponding measurements of humidity change $(\triangle M M R)$ obtained from analysis of the flow sampled through the RFP. Due to indications of a leak in the suction line, the data at the smallest velocity case was not included in these plots. In all cases, the humidity in the flow increased, as indicated by positive $\triangle M M R$ values, as the icing cloud interacted with the flow. However, $\triangle M M R$ values generally decreased linearly with increasing $\mathrm{RH}$. There is a noticeable spread between the experimental and simulation data, with the simulation data yielding larger humidity changes than the test data. As was the trend with total temperature, humidity changes at $87.5 \mathrm{kPa}$ were smaller than at $44.8 \mathrm{kPa}$.

\section{Discussion}

In the experiments, all cases produced a substantial decrease in total temperature as a result of the interaction with icing cloud, with the largest changes at the lowest (near zero) $\mathrm{RH}$ and decreasing in magnitude with increasing RH. This trend is expected, and is in agreement with simulation results, since evaporation is enhanced at lower RH thereby extracting more energy from the flow. There were smaller variations in the magnitude of $\Delta T_{0}$ with flow speed. If the smallest and medium velocity cases are compared, it shows an increase in the magnitude of $\Delta T_{0}$ with increase in velocity. On the other hand, the medium and largest velocity cases show a slight decrease in magnitude of $\Delta T_{0}$ with increase in flow speed.

The simulation results captured some of the same trends as the experiments. The best agreement was in the two larger velocity cases. The least agreement occurred in the lowest velocity and in the higher plenum pressure cases. The experimental points were limited in $\mathrm{RH}$ range relative to the simulation data due to icing effects at higher RH. One likely reason for these quantitative discrepancies is the 3D (or axisymmetric) nature of the cloud while the thermodynamic model is 1D. The experimental spray pattern generated a cloud near the axial centerline, and a cloudless annulus region. Simulation results can potentially predict greater magnitudes of change in both temperature and humidity as, experimentally, some mixing between the cloudfilled core and cloudless annulus regions potentially reduced the magnitudes of temperature and humidity (see further discussions in Bartkus et al.[Ref. 2]). Lastly in the higher RH cases, the propensity for icing or run back on the probe was found to be stronger. Even though we discarded test points with excessive icing, signal unsteadiness or improper recovery after the spray, there may still have been minor or subtle thermodynamic and flow effects, as discussed previously, on the measured flow that became more dominant with increased $\mathrm{RH}$.

The trends in the data, both experimental and simulation, helped infer some of the fundamental physical processes that can take place during these interactions. First, as the plenum humidity increases, the amount of cloud evaporation is reduced/suppressed, and therefore the magnitude of $\triangle M M R$ decreases. As a consequence, since less water is evaporated, less energy is removed from the air, and therefore the magnitude of $\Delta T_{0}$ decreases as well. Secondly, as the flow velocity is increased, residence time is decreased, reducing the time for thermodynamic exchange between the cloud and the freestream air. As a result, less evaporation occurs and the magnitude of $\Delta T_{0}$ and $\triangle \mathrm{MMR}$ decreases as velocity is increased. However, the experimental results did not precisely follow this expected trend with increase in flow speed. 

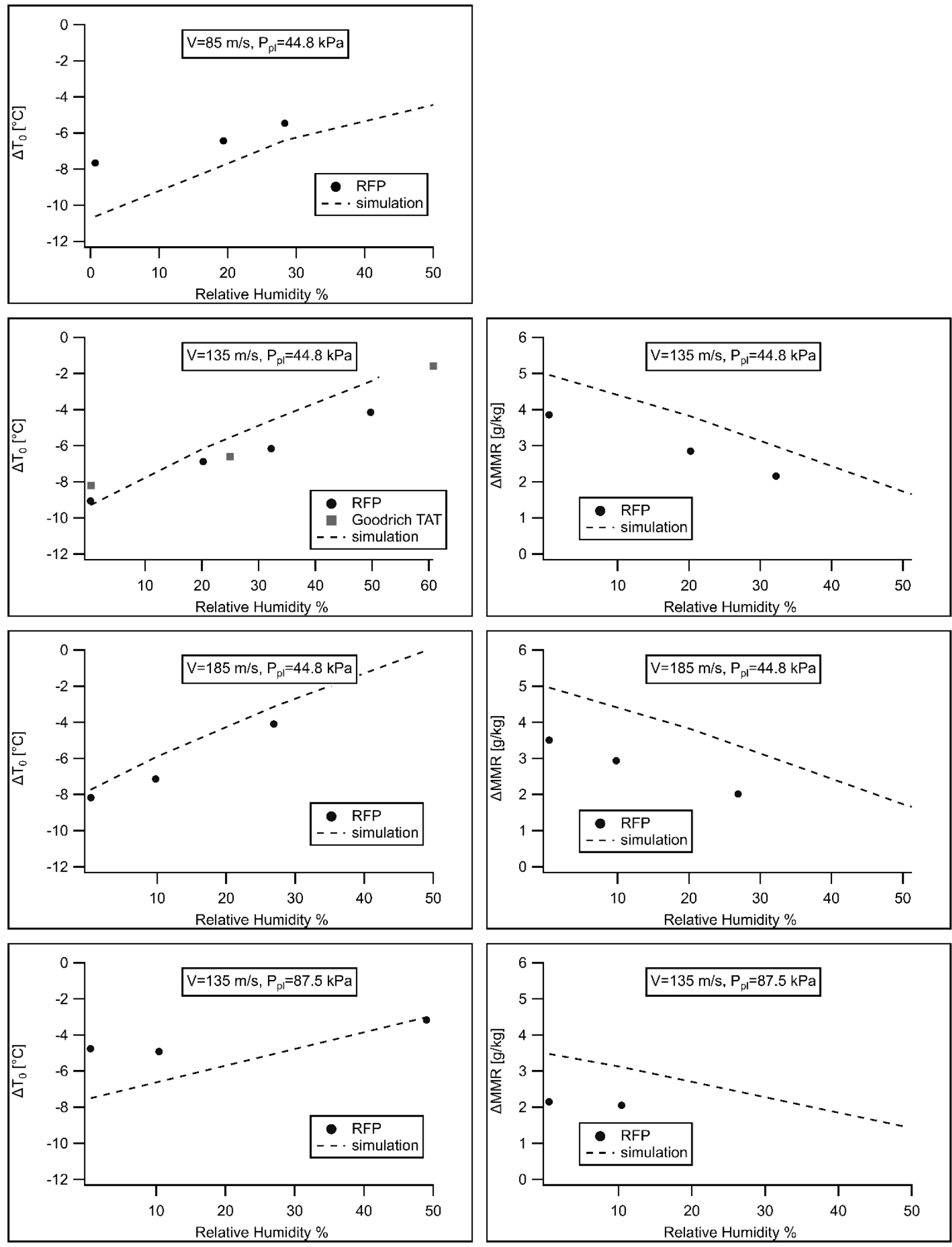

Figure 9. Total temperature and humidity changes after icing cloud spray activation - Total temperature plots for cases: $\left(\right.$ a) $\mathrm{V}=85 \mathrm{~m} / \mathrm{s}, P_{p l}=$ $44.8 \mathrm{kPa}$ (b) $\mathrm{V}=135 \mathrm{~m} / \mathrm{s}, P_{p l}=44.8 \mathrm{kPa},(\mathrm{c}), \mathrm{V}=185 \mathrm{~m} / \mathrm{s}, P_{p l}=44.8 \mathrm{kPa}$, (d) $\mathrm{V}=135 \mathrm{~m} / \mathrm{s}, P_{p l}=87.5 \mathrm{kPa}$; and $\Delta M M R$ plots for cases $:$ (e) $\mathrm{V}=135 \mathrm{~m} / \mathrm{s}, P_{p l}=44.8 \mathrm{kPa},(\mathrm{f}), \mathrm{V}=185 \mathrm{~m} / \mathrm{s}, P_{p l}=44.8 \mathrm{kPa},(\mathrm{g}) \mathrm{V}=135 \mathrm{~m} / \mathrm{s}, P_{p l}=87.5 \mathrm{kPa}$ 
The comparison between the RFP and Goodrich TAT probes in Fig. $9 \mathrm{~b}$ is also revealing of the characteristics of the performances and limitation of the probes. Recall that a current limitation of the TAT probe in our application is in understanding the effect of impinging water and ice on the temperature reading when deice heat is activated. By comparing the deice heat-off temperature (pre-spray) to the deice heat-on temperature during spray, good agreement was found between the two probes. However, the RFP measurements only went up to $30 \% \mathrm{RH}$ before icing-related contamination effects occurred. The TAT probe helped extend this range and provided a measurement at a RH of about $60 \%$ where it was close in value to the simulation curve. Therefore, it appears that the RFP can properly measure total temperature changes under mild to moderate icing conditions, as confirmed by comparison to modeling and the independent TAT measurement. This finding provides some confidence in the performance of both probes in this atmospheric flow regime.

\section{Conclusions}

A rearward facing probe capable of measuring total temperature and humidity was used in a series of icing cloud tests in the PSL. The probe incorporates a new contamination cap to help reduce ingested water. The cap was made from a thin ASA plastic to reduce the thermal capacity and conductivity of the probe body to improve the time response. As part of these tests, the performance of the RFP was characterized in the PSL flow environment under dry to significant icing conditions. The probe performed reasonably well over an extended range of altitude flows and in mild to moderate icing conditions. However, anomalous results were produced under more intense icing conditions. A CFD analysis of the flow around the probe body revealed that the trajectory of the flow brought it into close contact with the probe body prior to reaching the inlet, indicating the possibility that the ingested flow could be susceptible to convective and evaporative cooling particularly if ice builds up on the probe body. The experimental results showed that the total temperature decreases while the humidity increases as a result of the interaction with the icing cloud. The magnitude of the total temperature change generally decreased with increasing initial relative humidity of the flow. This is because as the plenum humidity increases, the amount of cloud evaporation is reduced/suppressed. The flow speed was shown to have a smaller effect on changes in total temperature and humidity. The experimental results were found to be in general agreement with the simulations using the thermodynamic TADICE model, particularly at higher flow speeds. Differences from the simulation were found at low velocity and at higher plenum pressure. The TADICE model helped show that conditions that promote greater amounts of evaporation and evaporative cooling, such as low facility $\mathrm{RH}$, and slower velocities (longer residence times), result in greater humidity and temperature changes. The present data will help further improve the design and operation of the probe. Improvements in the RFP measurements may come about through additional testing under a greater variety of test conditions and by better understanding the flow and thermal fields around the probe through CFD modeling, as well as better characterization of the ice accretion process on the probe.

\section{References}

1. Bartkus, T. P., Struk, P. M., Tsao, J. C., and Van Zante, J. F., "Numerical Analysis of Mixed-Phase Icing Cloud Simulations in the NASA Propulsion Systems Laboratory," 8th AIAA
Atmospheric and Space Environments Conference, AIAA, Washington D.C., 2016, doi: 10.2514/6.2016-3739.

2. Bartkus, T. P., Struk, P. M., and Tsao, J-C., "Comparisons of Mixed-Phase Icing Cloud Simulations with Experiments Conducted at the NASA Propulsion Systems Laboratory," 9th AIAA Atmospheric and Space Environments Conference, AIAA, Denver, CO, 2017, doi: 10.2514/6.2017-4243.

3. Agui, J. H., Struk, P. M., and Bartkus, T. P., "Total Temperature Measurements Using a Rearward Facing Probe in Supercooled Liquid Droplet and Ice Crystal Clouds," 2018 AIAA Atmospheric and Space Environments Conference, AIAA, Atlanta, GA, 2018, doi:10.2514/6.2018-3970.

4. Struk, P., Agui, J., Ratvasky, T., King, M., et al. "Ice-crystal icing accretion studies at the NASA Propulsion Systems Laboratory," SAE 2019 International Conference on Icing of Aircraft, Engines, and Structures, SAE International, Minneapolis, MN, 2019 (submitted for publication).

5. Van Zante, J. F., Ratvasky, T. P., Bencic, T. J. Challis, C. C., et al. " Update on the NASA Glenn Propulsion Systems Lab Icing and Ice Crystal Cloud Characterization (2017)" 2018 AIAA Atmospheric and Space Environments Conference, AIAA, Atlanta, GA, 2018, doi:10.2514/6.2018-3969.

6. Van Zante, J. F., Bencic, T. J., and Ratvasky, T. P., "Update on the NASA Glenn Propulsion Systems Lab Ice Crystal Cloud Characterization Update 2015," 8th AIAA Atmospheric and Space Environments Conference, AIAA, Washington D.C., 2016, doi: 10.2514/6.2016-3897.

7. Stickney, T.M., Shellow, M.W., and Thomspon, D.I. "Goodrich Total Temperature Sensors." Technical Report 5755.

8. The OpenFOAM Foundation, "OpenFOAM v6 User Guide" url:https://cfd.direct/openfoam/user-guide.

\section{Contact Information}

Juan H. Agui, NASA Glenn Research Center, 21000 Brookpark Rd., Cleveland, OH 44135, Email: Juan.H.Agui@ nasa.gov.

\section{Acknowledgments}

The authors wish to acknowledge the Advanced Aircraft Icing (AAI) sub-project of the NASA Advanced Air Transport Technology Project (AATT), under NASA's Advanced Air Vehicles Program (AAVP), for financial support for this work.

\section{Definitions/Abbreviations}

$\begin{array}{ll}\boldsymbol{\eta} & \text { Recovery correction } \\ \boldsymbol{\tau} & \text { Time constant } \\ \mathbf{C p} & \text { Specific heat capacity } \\ \mathbf{M} & \text { Mach number } \\ \mathbf{M M R} & \text { Mass Mixing Ratio } \\ \mathbf{R F P} & \text { Rearward Facing Probe } \\ \mathbf{R H} & \text { Relative Humidity }\end{array}$


slpm

Total Air Temperature

$\mathbf{T}_{\mathbf{0}, \mathbf{i}, \mathbf{f f f}}$

Plenum Total Temperature (=TPL)

TPL

$\mathbf{T}_{\mathbf{r}}$

TRFP $_{\text {RP }}$

TAT
Plenum Total Temperature measured using thermocouples in the slow moving flow of plenum

Recovery Temperature

Total Air Temperature measured by RFP

Total Air Temperature
V

Velocity

Subscripts

i

off

on
Facility inlet (just before spray bars)

Cloud-off

Cloud-on 


\section{Appendix}

Table 1. Temperature Measurement Data Table

\begin{tabular}{|l|c|c|c|c|c|c|c|c|c|}
\hline Symbol $\rightarrow$ & $\mathrm{P}_{0}$ & $\mathrm{U}_{\mathrm{e}}$ & $\mathrm{RH}_{0, \mathrm{i}, \text { avg }}$ & $\mathrm{T}_{0, \mathrm{i}, \text { off }}$ & $\mathrm{T}_{\mathrm{RFP}, \text { off }}$ & $\mathrm{T}_{0, \mathrm{i}, \text { on }}$ & $\mathrm{T}_{\mathrm{RFP}, \text { on }}$ & $\Delta \mathrm{T}_{\mathrm{RFP}}$ & $\Delta \mathrm{T}_{0}$ \\
\hline Units $\rightarrow$ & $\mathrm{kPa}$ & $\mathrm{m} / \mathrm{s}$ & $\%$ & ${ }^{\circ} \mathrm{C}$ & ${ }^{\circ} \mathrm{C}$ & ${ }^{\circ} \mathrm{C}$ & ${ }^{\circ} \mathrm{C}$ & ${ }^{\circ} \mathrm{C}$ & ${ }^{\circ} \mathrm{C}$ \\
\hline $\begin{array}{l}\text { Source } \rightarrow \\
\text { Escort } \downarrow\end{array}$ & Meas. & Calc. & Calc. & Meas. & Meas. & Meas. & Meas. & $\mathrm{Calc}^{1},{ }^{2}$ & Eq. $3^{2}$ \\
\hline
\end{tabular}

Target Conditions: $85 \mathrm{~m} / \mathrm{s}, \mathrm{P}_{0}=44.8 \mathrm{kPa}$ (6.5 psia)

\begin{tabular}{|l|l|l|l|l|l|}
\hline 231 & 6.49 & 82.9 & 0.7 & 7.2 & 5.8 \\
\hline 232 & 6.49 & 83.1 & 19.5 & 7.6 & 6.4 \\
\hline 233 & 6.49 & 83.1 & 28.3 & 7.4 & 6.2 \\
\hline $509^{3}$ & 6.49 & 83.9 & 50.7 & 7.3 & 6.5 \\
\hline $226^{3}$ & 6.49 & 83.5 & 57.2 & 7.5 & 6.7 \\
\hline
\end{tabular}

Target Conditions: $135 \mathrm{~m} / \mathrm{s}, \mathrm{P}_{0}=44.8 \mathrm{kPa}(6.5 \mathrm{psia})$

\begin{tabular}{|c|c|c|c|c|c|c|c|c|c|}
\hline 162 & 6.50 & 133.5 & 0.4 & 6.8 & 4.1 & 6.6 & -5.1 & -9.1 & -9.1 \\
\hline 163 & 6.50 & 133.7 & 20.3 & 7.1 & 4.5 & 7.2 & -2.4 & -6.9 & -6.9 \\
\hline 164 & 6.49 & 133.8 & 32.6 & 7.5 & 4.8 & 7.6 & -1.3 & -6.2 & -6.2 \\
\hline $429^{6}$ & 6.50 & 133.2 & 49.9 & 7.2 & 4.8 & 7.3 & 0.6 & -4.2 & -4.1 \\
\hline
\end{tabular}

TAT Probe Data

\begin{tabular}{|c|c|c|c|c|c|c|c|c|c|}
\hline Escort $\downarrow$ & $\mathrm{P}_{0}$ & $\mathrm{U}_{\mathrm{e}}$ & $\mathrm{RH}_{0, \mathrm{i} \text {,avg }}$ & $\mathrm{T}_{0, \mathrm{i} \text {, ff }}$ & $\mathrm{T}_{\mathrm{TAT} \text {,off }}$ & $\mathrm{T}_{0, \mathrm{i}, \text { on }}$ & $\mathrm{T}_{\mathrm{TAT}, \text { on }}$ & $\Delta \mathrm{T}_{\mathrm{TAT}^{2}}{ }$ & $\Delta \mathrm{T}_{0}$ \\
\hline 590 & 6.49 & 133.0 & 0.5 & 7.1 & $6.7^{4}$ & 7.1 & -1.5 & -8.2 & $\mathrm{~N} / \mathrm{A}$ \\
\hline 591 & 6.49 & 133.2 & 25.0 & $7.4^{5}$ & 7.05 & 7.5 & 1.4 & -5.6 & $\mathrm{~N} / \mathrm{A}$ \\
\hline 589 & 6.49 & 133.2 & 60.9 & 7.3 & 6.8 & 7.2 & 5.1 & -1.6 & $\mathrm{~N} / \mathrm{A}$ \\
\hline
\end{tabular}

Target Conditions: $185 \mathrm{~m} / \mathrm{s}, \mathrm{P}_{0}=44.8 \mathrm{kPa}$ (6.5 psia)

\begin{tabular}{|c|c|c|c|c|c|c|c|c|c|}
\hline 202 & 6.49 & 182.2 & 0.4 & 7.7 & 2.1 & 6.2 & -7.4 & -8.0 & -8.0 \\
\hline 203 & 6.49 & 182.3 & 9.9 & 6.9 & 1.4 & 7.1 & -5.5 & -7.0 & -7.0 \\
\hline 204 & 6.49 & 182.3 & 27.2 & 7.4 & 1.8 & 7.8 & -1.8 & -4.0 & -4.0 \\
\hline $197^{3}$ & 6.49 & 181.9 & 55.3 & 7.5 & 2.0 & 7.5 & $*$ & $*$ & $*$ \\
\hline \multicolumn{10}{|c|}{ Target Conditions: $135 \mathrm{~m} / \mathrm{s}, \mathrm{P}_{0}=87.6 \mathrm{kPa}$ (12.7 psia) } \\
\hline $252^{6}$ & 12.69 & 133.5 & 0.5 & 7.2 & 4.4 & 7.2 & -0.4 & -4.8 & -4.8 \\
\hline 250 & 12.69 & 133.5 & 10.4 & 7.3 & 4.5 & 7.3 & -0.4 & -4.9 & -4.9 \\
\hline $251^{6}$ & 12.69 & 133.6 & 49.1 & 7.6 & 4.5 & 7.7 & 1.4 & -3.2 & -3.2 \\
\hline
\end{tabular}

* Denotes poor data quality

\footnotetext{
${ }^{1} \Delta \mathrm{T}_{\mathrm{RFP}}$ in this column is calculated as $\mathrm{T}_{\mathrm{RFP}, \text { on }}-\mathrm{T}_{\mathrm{RFP}, \text { off. }}$

2 The quantity TPLon-TPLoff is subtracted from these columns to account for drift of the plenum temperature.

${ }^{3}$ Temperature data became contaminated during testing possibly due to water ingestion.

${ }^{4}$ TAT probe heat was active during this test point preventing direct comparison with other point in table. The value shown was estimated based on the other two data points.

${ }^{5}$ Values measured after cloud came off and TAT probe cooled once deice heat deactivated.

${ }^{6}$ Ice was on probe prior to spray from previous test. However, temperature data was useable.
}

Page 10 of 12 
Table 2. Humidity Measurement Data Table

\begin{tabular}{|l|c|c|c|c|c|c|}
\hline Symbol $\rightarrow$ & $\mathrm{RH}_{0, \mathrm{i}, \text { avg }}$ & $\mathrm{MMR}_{\mathrm{i}, \text { off }}$ & $\mathrm{MMR}_{\mathrm{e}, \text { off }}$ & $\mathrm{MMR}_{\mathrm{i}, \text { on }}$ & $\mathrm{MMR}_{\mathrm{e}, \text { on }}$ & $\Delta \mathrm{MMR}_{\mathrm{RFP}}$ \\
\hline Cloud $\rightarrow$ & \multicolumn{2}{|c|}{$\mathrm{Off}$} & \multicolumn{2}{|c|}{ On } & $\mathrm{g} / \mathrm{kg}$ \\
\hline \begin{tabular}{l} 
Units $\rightarrow$ \\
\hline $\begin{array}{l}\text { Source } \rightarrow \\
\text { Escort } \downarrow\end{array}$
\end{tabular} & $\%$ & $\mathrm{~g} / \mathrm{kg}$ & $\mathrm{g} / \mathrm{kg}$ & $\mathrm{g} / \mathrm{kg}$ & $\mathrm{g} / \mathrm{kg}$ & Calc. \\
\hline
\end{tabular}

Target Conditions: $85 \mathrm{~m} / \mathrm{s}, \mathrm{P}_{0}=44.8 \mathrm{kPa}$ (6.5 psia)

\begin{tabular}{|l|l|l|}
\hline $231^{7}$ & 0.7 & 0.1 \\
\hline $232^{7}$ & 19.5 & 2.9 \\
\hline $233^{7}$ & 28.3 & 4.1 \\
\hline $509^{7}$ & 50.7 & 7.3 \\
\hline $226^{7}$ & 57.2 & 8.3 \\
\hline
\end{tabular}

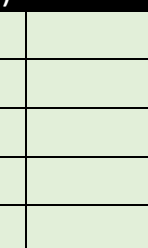

\begin{tabular}{|l|r|}
$*$ & 0.1 \\
$*$ & 2.8 \\
$*$ & 4.1 \\
$*$ & 7.2 \\
$*$ & 8.3
\end{tabular}

\begin{tabular}{|l|l|l|}
\hline 0.1 & $*$ & $*$ \\
\hline 2.8 & $*$ & $*$ \\
\hline 4.1 & $*$ & $*$ \\
\hline 7.2 & $*$ & $*$ \\
\hline 8.3 & $*$ & $*$ \\
\hline
\end{tabular}

Target Conditions: $135 \mathrm{~m} / \mathrm{s}, \mathrm{P}_{0}=44.8 \mathrm{kPa}$ (6.5 psia)

\begin{tabular}{|c|c|c|c|c|c|c|}
\hline 162 & 0.4 & 0.1 & 0.1 & 0.1 & 3.9 & 3.9 \\
\hline 163 & 20.3 & 2.9 & 2.8 & 2.9 & 5.6 & 2.8 \\
\hline 164 & 32.6 & 4.8 & 4.5 & 4.7 & 6.8 & 2.3 \\
\hline $429^{8}$ & 49.9 & 7.1 & $*$ & 7.1 & $*$ & $*$ \\
\hline
\end{tabular}

Target Conditions: $185 \mathrm{~m} / \mathrm{s}, \mathrm{P}_{0}=44.8 \mathrm{kPa}$ (6.5 psia)

\begin{tabular}{|c|c|c|c|c|c|c|}
\hline 202 & 0.4 & 0.1 & 0.1 & 0.1 & 3.6 & 3.5 \\
\hline 203 & 9.9 & 1.4 & 1.4 & 1.4 & 4.3 & 3.0 \\
\hline 204 & 27.2 & 3.9 & 3.8 & 4.0 & 5.8 & 2.0 \\
\hline $197^{8}$ & 55.3 & 8.1 & $*$ & 8.0 & $*$ & $*$ \\
\hline
\end{tabular}

Target Conditions: $135 \mathrm{~m} / \mathrm{s}, \mathrm{P}_{0}=87.6 \mathrm{kPa}$ (12.7 psia)

\begin{tabular}{|c|c|c|c|c|c|c|}
\hline 252 & 0.5 & 0.0 & 0.1 & 0.0 & 2.2 & 2.2 \\
\hline 250 & 10.4 & 0.8 & 0.8 & 0.8 & 2.8 & 2.0 \\
\hline $251^{8}$ & 49.1 & 3.7 & 3.7 & 3.7 & $*$ & $*$ \\
\hline
\end{tabular}

* Denotes poor data quality

\footnotetext{
${ }^{7}$ Probe ingested water early in test and was not able to recover to make humidity measurements for this dataset.

${ }^{8}$ Probe ingested water during test point contaminating humidity measurement.

Page 11 of 12
} 
Table 3. Experimental test conditions used for input parameters to TADICE model simulations

\begin{tabular}{|c|c|c|c|c|c|c|c|}
\hline $\begin{array}{c}\text { Escort } \\
\quad \#\end{array}$ & $\begin{array}{l}U_{e} \\
\mathrm{~m} / \mathrm{s}\end{array}$ & $\begin{array}{l}p_{0, i} \\
\mathrm{kPa}\end{array}$ & $\begin{array}{c}R H_{0, i} \\
\%\end{array}$ & $\begin{array}{l}T_{0, i} \\
{ }^{\mathrm{O}} \mathrm{C}\end{array}$ & $\begin{array}{c}T_{\text {water }, i} \\
{ }^{\mathrm{O}} \mathrm{C}\end{array}$ & $\begin{array}{l}M V D_{i} \\
\text { microns }\end{array}$ & $\begin{array}{c}T W C_{e, \text { target }} \\
\mathrm{g} / \mathrm{m}^{3}\end{array}$ \\
\hline 231 & 83 & 44.7 & 0.7 & 7.3 & 7.2 & 20 & 7.1 \\
\hline 232 & 83 & 44.7 & 19.5 & 7.6 & 7.2 & 20 & 7.1 \\
\hline 233 & 83 & 44.7 & 28.3 & 7.3 & 7.2 & 20 & 7.1 \\
\hline 509 & 84 & 44.8 & 50.7 & 7.2 & 6.9 & 20 & 7.0 \\
\hline 226 & 84 & 44.8 & 57.2 & 7.5 & 7.3 & 20 & 7.1 \\
\hline 162 & 133 & 44.8 & 0.4 & 6.6 & 7.3 & 20 & 6.5 \\
\hline 163 & 134 & 44.8 & 20.3 & 7.2 & 7.3 & 20 & 6.5 \\
\hline 164 & 134 & 44.8 & 32.6 & 7.5 & 7.3 & 20 & 6.5 \\
\hline 429 & 133 & 44.8 & 49.9 & 7.2 & 7.1 & 20 & 6.5 \\
\hline 165 & 133 & 44.8 & 51.2 & 7.1 & 7.3 & 20 & 6.5 \\
\hline 202 & 182 & 44.8 & 0.4 & 7.0 & 7.3 & 20 & 6.8 \\
\hline 203 & 182 & 44.8 & 9.9 & 7.0 & 7.3 & 20 & 6.8 \\
\hline 204 & 182 & 44.8 & 27.2 & 7.6 & 7.3 & 20 & 6.7 \\
\hline 197 & 182 & 44.8 & 55.3 & 7.5 & 7.2 & 20 & 6.8 \\
\hline 252 & 134 & 87.5 & 0.5 & 7.2 & 7.1 & 20 & 6.5 \\
\hline 250 & 134 & 87.5 & 10.4 & 7.3 & 7.0 & 20 & 6.5 \\
\hline 251 & 134 & 87.5 & 49.1 & 7.7 & 7.0 & 20 & 6.5 \\
\hline
\end{tabular}

